\title{
PERBANDINGAN PENGARUH LATIHAN UPHILL DENGAN INTERVAL TRAINING TERHADAP PENINGKATAN KECEPATAN LARI
}

\author{
Defri Mulyana $^{1)}$, Iman Rubiana ${ }^{2)}$ \\ ${ }^{1}$ Universitas Siliwangi \\ ${ }^{2}$ Universitas Siliwangi \\ e-mail: defrimulyana@unsil.ac.id ${ }^{1}, \underline{\text { imanrubiana@ unsil.ac.id }{ }^{2}}$
}

\begin{abstract}
Abstrak
Tujuan penelitian ini adalah untuk memperoleh informasi tentang perbandingan pengaruh latihan uphill dengan interval training terhadap peningkatan kecepatan lari pada siswa peserta ekstrakurikuler sepakbola SMA Negeri 10 Tasikmalaya dan informasi tentang bentuk latihan yang paling efektif di antara keduanya. Metode penelitian yang digunakan adalah metode eksperimen dengan teknik tes. Populasi penelitian yang digunakan adalah siswa Peserta Ekstrakurikuler Sepakbola SMA Negeri 10 Tasikmalaya sebanyak 32 orang yang dijadikan sampel sebanyak 30 orang. Berdasarkan hasil pengolahan data dengan uji statistik, t hitung 2,05 sama dengan t tabel 2,05 dan berada di dalam daerah penerimaan hipotesis, sehingga hipotesis nol (Ho) ditolak dan hipotesis kerja diterima. Dengan demikian, terdapat pengaruh yang berarti antara kelompok A dan kelompok B dalam meningkatkan kecepatan lari. Dengan demikian, bahwa latihan uphill lebih berpengaruh yang signifikan dalam meningkatkan keterampilan lari siswa peserta ekstrakurikuler sepakbola SMA Negeri 10 Tasikmalaya. Dari hasil penelitian ini disarankan agar para Pembina dan pelatih olahraga hendaknya selalu mencoba bentuk-bentuk latihan yang tepat sesuai dengan tujuan yang ingin dicapai agar hasil latihannya memuaskan. Hasil penelitian ini dapat dijadikan acuan dalam menyusun dan melaksanakan program latihan yang bertujuan meningkatkan kecepatan lari.
\end{abstract}

Kata Kunci : Latihan Uphil, Interval Training, Kecepatan Lari

\begin{abstract}
The purpose of this study was to obtain information about the comparison of the effect of uphill training with interval training on increasing running speed in students participating in extracurricular football at SMA Negeri 10 Tasikmalaya and information about the most effective form of training between the two. The research method used is an experimental method with test techniques. The research population used was 32 students who participated in the extracurricular football at SMA Negeri 10 Tasikmalaya, who were sampled as many as 30 people. Based on the results of data processing with statistical tests, $t$ count 2.05 is the same as t table 2.05 and is in the area of acceptance of the hypothesis, so the null hypothesis $(\mathrm{Ho})$ is rejected and the working hypothesis is accepted. Thus, there is a significant effect between group $A$ and group $B$ in increasing running speed. Thus, that uphill training has a significant effect on improving the running skills of the students participating in the extracurricular football at SMA Negeri
\end{abstract}


10 Tasikmalaya. From the results of this study it is suggested that the coaches and sports coaches should always try the right forms of training in accordance with the objectives to be achieved so that the training results are satisfactory. The results of this study can be used as a reference in preparing and implementing an exercise program aimed at increasing running speed.

Keywords: Uphil Training, Interval Training, Running Speed

\section{Pendahuluan}

Latihan pembinaan kondisi fisik atau kesegaran jasmani dewasa ini merupakan salah satu bagian terpenting untuk semua latihan pada setiap cabang olahraga, terlebih pada cabang olahraga atletik. Tujuanya adalah membentuk kondisi tubuh sebagai dasar dalam meningkatkan ketahanan dan kesegaranya, terutama dalam menghadapi kalau atlet harus tampil di gelanggang pertandingan.

Oleh karena itu untuk meningkatkan kesegaran jasmani dibutuhkan beberapa latihan yang sesuai, dalam hal ini Jarver (2015:16) mengemukakan bahwa:

Dari berbagai klasifikasi latihan jasmani, dimana kesegaran jasmani merupakan komponen penting yang harus dicapai, secara umum dapat dibagi dalam dua kategori.

1. Latihan jantung dan pernapasan

2. Latihan otot.

Bagi seorang pelari dituntut kemampuanya dalam waktu reaksi (reaction time), akselerasi (acceleration), kecepatan maksimal (maximum speed), dan daya tahan kecepatan (speed endurance). Oleh karena itu unsur-unsur tersebut perlu terus ditingkatkan melalui proses latihan.

Adapun upaya untuk mengembangkan kemampuankemampuan tersebut diatas, penekanan latihan kondisi fisik tidak hanya terbatas pada bentuk-bentuk latihan kecepatan saja. Namun demikian komponen-komponen kondisi fisik lainya seperti unsur kekuatan juga harus diberikan, seperti yang di ungkapkan Sajoto (2014:97) bahwa "meningkatkan kekuatan kaki adalah hal utama untuk meningkatkan panjangnya langkah. Semakin kuat kaki-kaki para pelari, semakin besar tenaga yang dapat digunakan oleh kaki untuk mendorong badan ke depan dari tanah pada setiap langkah".

Berdasarkan pendapat tersebut di atas, jelas bahwa unsur kekuatan pun sangat dibutuhkan dalam menunjang keberhasilan pelari, karena kekuatan otot-otot kaki dapat meningkatkan kemampuan panjang langkah, serta menunjang kecepatan langkah sebagai dampak kekuatan kaki saat bertumpu/menolak pada lintasan, serta meningkatkan frekuensi langkah. Sehubungan dengan hal itu perlu diberikan bentuk-bentuk latihan yang mampu meningkatkan unsur-unsur tersebut di atas.

Kecepatan menurut Harsono (2001:36) adalah "kemampuan untuk melakukan gerakan-gerakan sejenis secara berturut-turut dalam waktu yang sesingkat-singkatnya, atau kemampuan untuk menempuh suatu jarak dalam waktu yang cepat". Sejalan dengan pendapat Harsono, Badriah (2002:26) mengemukakan bahwa "kecepatan adalah kemampuan tubuh untuk menempuh atau melakukan gerakan 
secara berturut-turut dalam waktu yang singkat". Oleh karena itu kecepatan merupakan salah satu komponen kondisi fisik dasar yang lazim untuk menunjang keberhasilan seorang atlet dalam menghadapi suatu pertandingan.

Terdapat berbagai macam bentuk latihan untuk meningkatkan kecepatan, ada juga bentuk latihan untuk meningkatkan kecepatan seperti latihan uphill yaitu lari naik bukit untuk meningkatkan dynamic strength dalam otot-otot tungkai, dynamic strength juga bisa dikembangkan dengan lari tahanan dinamis, pasir salju, atau lapangan yang empuk. Selanjutnya Harsono (2001:36) mengemukakan bahwa "bentuk latihan untuk meningkatkan kecepatan adalah 1) Interval training, 2) Lari akselerasi dan diselingi oleh lari deselerasi, 3) Uphill dan downhill, 4) Repetition training, 5) Sprint training, 6) Hollow sprint, 7) Pick-up sprint". Sesuai dengan tujuannya, setiap bentuk latihan mempunyai ciri-ciri tertentu.

Berkaitan dengan hal ini, Suharno (1993:49) mengemukakan ciri-ciri umum latihan kecepatan sebagai berikut : 1) Harus ada bentuk latihan cyclic dan acyclic, 2) Selalu mengejar waktu yang paling pendek (cepat), 3) Pengukuran waktu mulai dari perangsangan (stimulus) dan jawaban (respons) dari pelatih, 4) Metode yang biasa dignakan ialah interval running, interval training, metode pertandingan (competition method) dan metode bermain kecepatan (speed play).

Pada kesempatan penelitian ini penulis akan membandingkan antara bentuk latihan Uphill (lari naik bukit) dengan Inteval training terhadap peningkatan kecepatan lari. Bentuk latihan Uphill (lari naik bukit) yaitu suatu sistem/bentuk latihan lari yang dilaksanakan di tempat/lintasan (berupa tanah yang berbukit sehingga membentuk tanjakan-tanjakan). Sedangkan Interval training yaitu sistem latihan yang diselingi oleh interval-interval yang berupa masamasa istirahat, yang dapat meningkatkan dan mengembangkan daya tahan jantung dan paru-paru yang memaksa tubuh untuk bekerja dalam waktu yang lama. Interval training merupakan cara latihan yang harus dimasukkan dalam progam latihan keseluruhan ataupun suatu sistem latihan untuk melatih daya tahan bisa juga digunakan unutk melatih stamina. Bentuk latihan ini ditujukan untuk melatih kecepatan lari.atau renang, karena itu, jaraknya di pecah-pecah

dalam jarak-jarak pendek agar orang bisa lari dengan kecepatan tinggi.

Bertitik tolak dari paparan permasalahan diatas penulis tertarik untuk mengkaji pengaruh bentuk latihan Uphill (lari naik bukit) dengan Interval training terhadap peningkatan kecepatan lari.

Bentuk latihan Uphill (lari naik bukit) dan Interval training dijadikan kajian dalam penelitian ini. Didasarkan pada pemikiran penulis melihat bahwa di wilayah Kecamatan Tamansari Kota Tasikmalaya. Di lingkungan Sekolah Menengah Atas Negeri 8 Tasikmalaya, dapat digambarkan bahwa keadaan alam sekitarnya masih terdapat gunung dan bukit, dan juga terdapat lapangan yang cukup luas yang bias digunakan untuk latihan Interval training. Dengan memperhatikan keuntungan dan kerugian masing-masing bentuk latihan tersebut perlu diteliti perbandingan pengaruh Latihan Uphill dengan Interval training terhadap peningkatan kecepatan lari (Eksperimen pada Siswa Putra Ekstrakurikuler Sepakbola SMA Negeri 10 Tasikmalaya. 
Penjelesan singkat mengenai dimana lokasi penelitian,kapan penelitian dilaksanakan, bahan atau intrumen apa yang digunakan dan metode apa yang digunakan untuk melakukan penelitian atau memecahkan masalah.

\section{BAHAN DAN METODE/METODOLOGI}

Dalam suatu penelitian eksperimental perlu suatu desain penelitian yang tepat, sesuai dengan kebutuhan variabel-variabel yang tekandung dalam desain penelitian. Desain penelitian dalam penelitian ini adalah "pre test dan post-test design" yang digambarkan sebagai berikut :

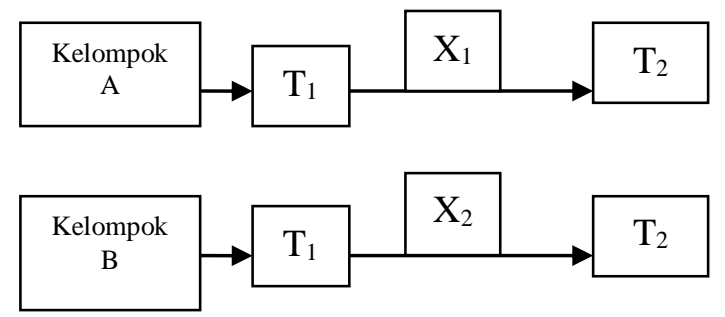

Arikunto (2002:101) menjelaskan bahwa "variabel yang mempengaruhi disebut penyebab disebut variabel bebas atau independent variabel (X), sedangakn variabel akibat disebut variabel tak bebas, variabel tergantung, variabel terikat atau independent variable (Y)". Latihan uphill dan interval training merupakan variabel bebas dan peningkatan kecepatan lari merupakan variabel terikat.

Instrument penelitian yang digunakan untuk memperoleh data penelitian ini adalah tes lari cepat 50 meter. Hal ini didasari oleh pendapat Nurhasan dan Abdul Narlan (2001:129) bahwa "kecepatan umumnya diukur dengan lari jarak pendek"

Pada pelaksanaannya, penulis mengambil sebagian dari populasi untuk dijadikan sampel sesuai dengan kebutuhan penelitian dengan kriteria, sampel dalam keadaan sehat. Setelah diteliti maka sampel yang memungkinkan untuk mengikuti pelatihan sebanyak 30 orang. Artinya dalam menentukan sampel ini penulis menggunakan teknik total sampling.

\section{Hasil dan Pembahasan}

Sesuai dengan permasalahan yang penulis bahas dalam penelitian ini, berikut ini penulis kemukakan data penelitian berupa hasil tes kecepatan sebagai instrumen yang digunakan dalam mengukur kecepatan lari siswa sebelum diberi perlakuan dan sesudah diberi perlakuan. Data hasil tes awal dan tes akhir dari kelompok A dan kelompok B dapat dilihat pada lampiran.

Dari hasil perhitungan analisis statistik didapatkan gambaran data nilai rata-rata, standar deviasi dan varians dari tes awal dan tes akhir kelompok A dan kelompok B. hasilnya dapt dilihat pada tabel 4.1 di bawah ini.

Tabel 4.1

Hasil Perhitungan Rata-rata

Standar, dan Varians dari Kedua Kelompok Latihan

\begin{tabular}{cccc} 
Variabel & $\begin{array}{c}\text { Rata- } \\
\text { rata }\end{array}$ & $\begin{array}{c}\text { Simpangan } \\
\text { Baku }\end{array}$ & Varians \\
\hline Tes Awal & \multicolumn{2}{c}{ Kelompok A } \\
Tes Akhir & 7,34 & 0,26 & 0,0676 \\
\multicolumn{4}{c}{ Kelompok B } \\
Tes Awal & 7,25 & 0,29 & 0,0625 \\
Tes Akhir & 6,14 & 0,21 & 0,0841 \\
\hline
\end{tabular}

A. Pengujian PersyaratanAnalisis

1. Hasil Perhitungan Distribusi Normal dari Kedua Kelompok Latihan

Setelah diketahui nilai rata-rata, standar deviasi, dan varians dari kedua kelompok tersebut, maka langkah selanjutnya adalah melakukan pengujian normalitas data. Pengujian 
menggunakan pengujian Chi-Kuadrat. Hasil pengujian akan menentukan pendekatan mana yang akan dipergunakan dalam analisis data apakah pendekatan peremetik atau non parametik. Pendekatan parametik digunakan apabila tes normal, sedangkan pendekatan non parametik digunakan apabila hasil tes tersebut tidak normal.

Setelah proses perhitungan dilakukan, maka diperoleh dasil seperti dalam tabel 4.2 di bawah ini.

\section{Tabel 4.2}

Hasil Pengujian Distribusi Normal dari Masing-masing Kelompok

Latihan

\begin{tabular}{cccc} 
Variabel & $\begin{array}{c}\text { Nilai } \\
\text { Chi- } \\
\text { kuadrat } \\
\text { Hitung }\end{array}$ & $\begin{array}{c}\text { Nilai Chi- } \\
\text { kuadrat } \\
\text { Tabel } \\
(\boldsymbol{\alpha}=\mathbf{0 , 0 5})\end{array}$ & Hasil \\
\hline $\begin{array}{c}\text { Kelompok A } \\
\text { Tes }\end{array}$ & 2,91 & 5,99 & Normal \\
$\begin{array}{c}\text { Awal } \\
\text { Tes }\end{array}$ & 2,65 & 5,99 & Normal \\
Akhir & Kelompok B & \\
Tes & 3,21 & 5,99 & Normal \\
Awal & 3,18 & 5,99 & Normal \\
Tes & & & \\
Akhir & \multicolumn{3}{c}{} \\
\hline
\end{tabular}

2. Hasil Pengujian Homogenitas Data dari Kedua Kelompok Latihan

Untuk menguji hopotesis dengan rumus statistik $\mathrm{t}$, maka data tersebut harus homogenitas. Pengujian homogenitas data menggunakan rumus homogenitas. Untuk lebih jelasnya hasil perhitungan dapat dilihat pada tabel 4.3 di bawah ini.

Tabel 4.3 Hasil Pengujian Homogenitas Data
dari Kedua Kelompok Latihan

\begin{tabular}{|c|c|c|c|}
\hline Variabel & $\begin{array}{l}\text { Nilai } \\
\text { F }_{\text {hitung }}\end{array}$ & $\begin{array}{c}\text { Nilai } F \\
\text { hitung } \\
\text { pada } \\
(\alpha=0,05 \\
) \\
(14: 14)\end{array}$ & Hasil \\
\hline$\underset{\text { A }}{\text { Kelompok }}$ & 1,08 & 2,48 & Homogen \\
\hline $\begin{array}{c}\text { Kelompok } \\
\text { B }\end{array}$ & 1,91 & 2,48 & Homogen \\
\hline
\end{tabular}

\section{B. Pengujian Hipotesis}

Sehubungan dengan data dalam penelitian ini berdistribusi normal dan homogen, maka statistik yang digunakan adalah parametik. Dengan demikian untuk keperluan hipotesis penelitian, ditempuh analisis statistik dengan menggunakan uji-t.

\section{Hasil analisis Data Latihan}

Kelompok A (Lari Uphill)

Pengujian hipotesis bertujuan untuk membuktikan apakah hipotesis yang diajukan dalam penelitian ini diterima atau tidak. Untuk membuktikan kebenaran hipotesis yang diajukan tersebut, maka dipergunakan uji-t. hasil uji-t untuk kelompok A dapat dilihat pada tabel 4.4 di bawah ini.

\section{Tabel 4.4}

\section{Analisis Data Peningkatan Hasil Latihan Kelompok A}

\begin{tabular}{cccc} 
Variabel & $\begin{array}{c}\text { Nilai } \\
\mathbf{t} \\
\text { hitung }\end{array}$ & $\begin{array}{c}\text { Nilai t } \\
\text { hitung } \\
\text { pada } \\
(\boldsymbol{\alpha}=\mathbf{0 , 0 5}) \\
\mathbf{d k}=\mathbf{2 8}\end{array}$ & Varians \\
& & & \\
\hline $\begin{array}{c}\text { Kelompok } \\
\text { Tes Awal }\end{array}$ & 12,47 & 2,05 & Signifikan \\
\begin{tabular}{c} 
Tes Akhir \\
\hline
\end{tabular} & & & \\
\hline
\end{tabular}

Berdasarkan tabel di atas dapat dilihat bahwa $t$ hitung lebih besar dari $t$ tabel. ini berarti $t$ hitung berada di luar penerimaan hipotesis. 
2. Hasil Analisis Data Latihan Kelompok B (Lari Interval Training)

Untuk membuktikan kebenaran hipotesis yang diajukan tersebut, digunakan uji perbedaan dan rata-rata yaitu Uji-t. uji ini untuk mengetahui ada tidaknya perbedaan yang berarti terhadap hipotesis yang diajukan. Hasil Uji-t untuk kelompok B dapat dilihat pada tabel 4.5 di bawah ini.

Tabel 4.5

Analisis Data Peningkatan Hasil Latihan Kelompok B

\begin{tabular}{cccc} 
Variabel & $\begin{array}{c}\text { Nilai } \\
\mathbf{t} \\
\text { hitung }\end{array}$ & $\begin{array}{c}\text { Nilai t } \\
\text { hitung } \mathbf{p a d a} \\
(\mathbf{\alpha}=\mathbf{0 , 0 5}) \\
\mathbf{d k}=\mathbf{2 8}\end{array}$ & Hasil \\
\hline $\begin{array}{c}\text { Kelompok } \\
\text { Tes Awal } \\
\text { Tes Akhir }\end{array}$ & 12,33 & 2,05 & Signifikan \\
\hline
\end{tabular}

Dari tabel tersebut dapat dilihat bahwa $t$ hitung lebih besar dari $t$ tabel. Ini berarti $t$ hitung di luar batas penerimaan hipotesis, sehingga hipotesis (Ho) ditolak dan hipotesis kerja diterima. Dengan demikian, latihan lari interval training mempunyai pengaruh yang lebih berarti terhadap peningkatan kecepatan lari dapat diterima dan terbukti.

\section{Hasil Analisis Data Perbedaan Keceparan Lari antara kelompok A dan Kelompok B}

Karena data distribusi normal dan homogen, maka hipotesis diuji dengan menggunakan Uji-t. uji ini bertujuan untuk mengetahui ada tidaknya perbedaan peningkatan yang berarti terhadap hipotesis yang diajukan. Hasil pengujian hipotesis perbedaan peningkatan latihan antara kelompok A dan kelompok dapat dilihat pada tabel 4.6 di bawah ini.
Tabel 4.6

Hasil Analisis Data Perbadaaan Peningkatan Hasil Latihan Kelompok A dengan Kelompok B

\begin{tabular}{cccc} 
Variabel & $\overline{\boldsymbol{x}}$ & $\begin{array}{c}\mathbf{t} \text { tabel } \\
\text { dengan } \\
(\boldsymbol{\alpha}= \\
\end{array}$ & $\begin{array}{c}\mathbf{t} \\
\text { hitung } \\
\mathbf{0 , 0 5}) \mathbf{d k} \\
\mathbf{= 2 8}\end{array}$ \\
\hline $\begin{array}{c}\text { Kelompok } \\
\mathbf{A}\end{array}$ & 1,15 & 2,05 & 2,05 \\
\hline
\end{tabular}
Kelompok

B

Dari tabel tersebut dapat dilihat bahwa $t$ hitung sama dengan $t$ tabel dan berada di dalam daerah penerimaan hipotesis, sehingga hipotesis nol (Ho) ditolak dan hipotesis kerja diterima. Dengan demikian, terdapat pengaruh yang berarti antara kelompok A dan kelompok B dalam meningkatkan kecepatan lari. Dengan demikian, bahwa latihan uphill lebih berpengaruh yang signifikan dalam meningkatkan keterampilan lari siswa peserta ekstrakurikuler sepakbola SMA Negeri 10 Tasikmalaya.

\section{KESIMPULAN DAN SARAN}

\section{Simpulan}

Sesuai dengan analisis dan pembahasan hasil penelitian yang diperoleh, maka dapat disimpulkan hal-hal sebagai berikut :

1. Latihan lari uphill berpengaruh secara berarti terhadap peningkatan kecepatan lari pada siswa peserta ekstrakurikuler sepakbola SMA Negeri 10 Tasikmalaya.

2. Latihan lari interval training berpengaruh secara berarti terhadap peningkatan kecepatan lari pada siswa peserta ekstrakurikuler sepakbola SMA Negeri 10 Tasikmalaya. 
3. Latihan uphill lebih berpengaruh secara berarti dari pada latihan lari interval training pada siswa peserta ekstrakurikuler sepakbola SMA Negeri 10 Tasikmalaya.

\section{Saran}

Berdasarkan hasil penelitian tersebut di atas, maka penulis mengajukan saran sebagai berikut :

1. Kepada guru pendidikan jasmani, untuk dapat menerapkan latihan lari uphill dan interval training, karena telah terbukti secara ilmiah dapat meningkatkan kecepatan lari.

2. Bagi peneliti lain yang berminat pada masalah yang sama, menyarankan agar melakukan penelitian lebih lanjut dengan ruang lingkup yang lebih luas, misalnya dengan sampel yang lebih luas.

3. Penelitian lebih lanjut diharapkan terhadap aspek-aspek dan metode latihan lainnya dengan menggunakan sampel yang lebih besa dan pelaksanaanya yang lebih cermat.

\section{Daftar Pustaka}

Arikunto, Suharsimi. (2002). Metodologi Penelitian. Jakarta : Rineka Cipta

Badriah, Dewi L. (2002). Fisiologi Olahraga dalam Perspektif dan Praktik Bandung : Pustaka Ramadhan.

Badriah Dewi L. (2006). Metodologi Penelitian Ilmu-ilmu

Kesehatan. Bandung : Multazam.

Harsono. (2001). Latihan Kondisi Fisik. Bandung. FPOK UPI
Jarver, Jess. (2006). Belajar dan Berlatih Atletik. Bandung. Pionir Jaya

Nurhasan dan Abdul Narlan. (2001). Tes dan Pengukuran Pendidikan Olahraga. Tasikmalaya : PJKR FKIP UNSIL.

Sajoto, M. (2014). Peningkatan \& Pembinaan Kekuatan Kondisi Fisik dalamOlahraga Semarang: EFF Dahara Prize.

Suharno, HP. (1993). Metodologi Pelatihan. Yogyakarta : FPOK IKIP Yogyakarta. 